\title{
Das Wissen der Poesie
}




\section{linguae \& litterae}

Publications of the School of Language \& Literature Freiburg Institute for Advanced Studies

\section{Edited by}

Peter Auer, Gesa von Essen, Werner Frick

Editorial Board

Michel Espagne (Paris), Marino Freschi (Rom), Ekkehard König (Berlin), Michael Lackner (Erlangen-Nürnberg), Per Linell (Linköping), Angelika Linke (Zürich), Christine Maillard (Strasbourg), Lorenza Mondada (Basel), Pieter Muysken (Nijmegen), Wolfgang Raible (Freiburg), Monika Schmitz-Emans (Bochum)

\section{Volume 52}




\section{Das Wissen der Poesie}

Lyrik, Versepik und die Wissenschaften im 19. Jahrhundert

Herausgegeben von Henning Hufnagel und Olav Krämer

\section{DE GRUYTER}


ISBN 978-3-11-034839-2

e-ISBN (PDF) 978-3-11-034851-4

e-ISBN (EPUB) 978-3-11-038399-7

ISSN 1869-7054

Library of Congress Cataloging-in-Publication Data

A CIP catalog record for this book has been applied for at the Library of Congress.

Bibliografische Information der Deutschen Nationalbibliothek

Die Deutsche Nationalbibliothek verzeichnet diese Publikation in der Deutschen Nationalbibliografie; detaillierte bibliografische Daten sind im Internet über http://dnb.dnb.de abrufbar.

(c) 2015 Walter de Gruyter GmbH, Berlin/Boston

Satz: Johanna Boy, Brennberg

Druck: Hubert \& Co. GmbH \& Co. KG, Göttingen

@ Gedruckt auf säurefreiem Papier

Printed in Germany

www.degruyter.com 